\title{
Teleworking and technostress: early consequences of a COVID-19 lockdown
}

\author{
Sonia Camacho ${ }^{1}$ (I) . Andrés Barrios ${ }^{1}$
}

Received: 12 July 2021 / Accepted: 5 January 2022 / Published online: 22 January 2022

(c) The Author(s), under exclusive licence to Springer-Verlag London Ltd., part of Springer Nature 2022

\begin{abstract}
This paper analyzes teleworkers' technostress evolution over time, as well as its effects on these individuals' work-related well-being over time. The proposed research model was tested using a survey-based longitudinal study with individuals that forcibly moved to teleworking in the context of a COVID-19 lockdown at two points in time (T0 and T1). Results indicate that two techno-stressors (work-home conflict and work overload) generated strain in teleworkers, which in turn decreased their satisfaction with telework and perceived job performance. In addition, teleworkers experienced two types of enduring technostress: synchronous effect (i.e., stressors generating strain at T1), and a cumulative reverse causation effect (i.e., strain at $\mathrm{T} 0$ has an effect on stressors at T1). These findings contribute to cognition, work, and technology literature by providing a more complete understanding of teleworkers' technostress and its possible cumulative effects over time. Practical insights for managing technostress when moving to and remaining in teleworking are provided.
\end{abstract}

Keywords Technostress · Teleworking · COVID-19

\section{Introduction}

Work is part of our well-being and a key driver of a person's health (Leka et al. 2003). At the beginning of 2020, the COVID-19 outbreak affected people's working practices worldwide. Governments from all over the world implemented different social distancing policies (e.g., self-isolation periods, lockdowns) to prevent the coronavirus disease. It is estimated that about $81 \%$ of the worldwide workforce has been affected by some form of lockdown measures due to the pandemic (International Labour Organization 2020). Consequently, companies were forced to move their employees to continue their job activities from home (BelzuneguiEraso and Erro-Garcés 2020). Teleworking, defined as working outside the workplace using ICTs ${ }^{1}$ (Verbeke et al. 2008), became a job alternative for many individuals during the pandemic. However, this practice posed new occupational health and safety threats, as workers had to deal with a different work environment that involves an increased use of information and communication technologies (ICT).

Sonia Camacho

so-camac@uniandes.edu.co

1 School of Management, Universidad de los Andes, Carrera 1 18A-12, 111711 Bogotá, Colombia
International organizations developed recommendations and standards to manage the impact of the pandemic on workers' psychological health and well-being (e.g., ISO/PAS 45005).

Teleworking is an established topic of study in the work and technology fields (see Bailey and Kurland 2002 for a review), and studies have determined how this working practice alters the way in which workers collaborate, interact, and contribute to their company. Advantages of teleworking include reduced time and cost overhead due to travel, increased job autonomy, time flexibility, and job satisfaction (Nilles 1997; ter Hoeven and van Zoonen 2015). On the other hand, teleworking includes challenges, such as social isolation, work-home conflicts (Tietze and Musson 2005), work overload (Kelliher and Anderson 2010), lack of a sense of organizational belonging (Kossek et al. 2015), and psychological distress (Chesley 2014).

Teleworking's unique work environment creates different demands for employees that, if not effectively managed, might create stress (Weinert et al. 2015). A particular type of stress experienced by teleworkers relates to their inability to cope with new ICT requirements in a healthy way, also known as technostress (Tarafdar et al.

\footnotetext{
${ }^{1}$ Despite the definition of teleworking is not necessarily bound to employees' home, the focus of this study is home-based teleworking, as it is the modality used in the prevention of COVID-19.
} 
2011). Previous studies have found that technostress can cause a variety of negative consequences to workers' personal and professional lives including decreased wellbeing (Fuglseth and Sørebø 2014), increased exhaustion (Maier et al. 2015a), lower job satisfaction, increased risk of job burnout, decreased job engagement (Srivastava et al. 2015), and work withdrawal (Park and Haun 2018). These consequences cost companies a large amount of money (Tu et al. 2005). Despite the importance of technostress' consequences for individuals and companies, only a few studies have analyzed technostress in the teleworking context, and its effects on job satisfaction (Estrada-Muñoz et al. 2021; López-Araujo and Osca Segovia 2008; Suh and Lee 2017; Weinert et al. 2015). Moreover, work and stress literature remarks that the negative effects of stress vary over time and manifest beyond the point of its occurrence (Zapf et al. 1996). This depends on the continuity of the stressors (Ford et al. 2014) or individuals' adaptation to them (Ritter et al. 2016). When experiencing stress, individuals develop feedback loops implementing behavioral, cognitional, and perceptual coping strategies to reappraise the situation and react accordingly until a tolerable state is reached (Hauk et al. 2019; Weinert and Weitzel 2019). Coping strategies are thus useful to manage the temporal effects of stress (see ISO 45003 ISO 2021; Lazarus and Folkman 1984) and organizational culture (e.g., involvement in decision-making, good team working) can act as a buffer for employees' stress (Michie 2002). Despite these important findings, and to the best of the authors' knowledge, no study has analyzed technostress evolution over time in the teleworking context. For these reasons, this study's research question is: what are the temporal effects of teleworkers' technostress?

To address this question, this study developed a theoryled research model that examines how teleworkers experience different techno-stressors that in turn affect strain with emotional (satisfaction with telework) and behavioral (perceived job performance) work-related well-being outcomes. This model was empirically tested with a longitudinal research design at two points in time within two months with workers that forcibly moved to teleworking due to a COVID19 lockdown. Results indicate that techno-stressors create an initial effect over strain that reduces employees' satisfaction with telework and perceptions of job performance. These techno-stressors are shown to have a cumulative effect, having a synchronous and reverse causation effects on strain, decreasing further the work-related well-being outcomes. These results provide researchers with new elements to longitudinally analyze teleworkers' technostress and its effect on job performance. In addition, results provide practitioners and policy-makers with meaningful insights that complement current recommendations to prevent workers' stress and to refine future transitions to teleworking.

\section{Literature review}

\subsection{Technostress}

Contemporary theories of stress define it as a negative emotional experience that occurs when individuals perceive themselves to be subject of environmental demands with which they cannot cope (Cox and Griffiths 2010). Stress has been operationalized in the stressor-strain model, which involves both the environmental demands and individuals' appraisals of them (Khan and Byosiere 1992). In this model, individuals face particular environmental demands (stressors). When those demands exceed individuals' abilities and available resources, they generate an immediate emotional negative reaction (strain) (Lazarus and Folkman 1984). In the occupational domain, work-related stress (WRS) is the negative response people have to excessive pressures or other types of demands placed on them at work, which exceed their capabilities. According to the intensity, duration, and temporal pattern of the demands, the related strain can lead to negative psychological and behavioral consequences, decreasing workers' well-being (Burns et al. 2016) and organizations' productivity (Dollard et al. 2000) in the short and long terms.

The increased use of ICTs in the workplace has created a work environment with new demands. End users' inability to fulfill such demands leads them to experience stress, a phenomenon that has been coined as technostress (RaguNathan et al. 2008). Some of the new demands associated with the organizational use of ICT causing technostress include application multitasking, constant connectivity, information overload, and technical problems (Tarafdar et al. 2010). Technostress brings about negative consequences for workers and organizations, such as reduced productivity and dissatisfaction with work (Tarafdar et al. 2007). The stressor-strain process model in relation to ICTs shows that technostress starts with the presence of (1) technology-affected environmental conditions, which the individual appraises as a (2) demand or techno-stressor that significantly taxes his or her resources, and (3) leads to strain (i.e., a negative emotional response, such as fear or anxiety), with (4) different negative psychological (e.g., decreased job satisfaction) and behavioral (e.g., decreased individual productivity) outcomes (Tarafdar et al. 2010).

Technostress was first operationalized as stress-producing conditions referred to as technostress creators (RaguNathan et al. 2008), including: techno-overload (i.e., ICT makes employees work more and faster), techno-invasion (i.e., employees can be reached anywhere and anytime), techno-complexity (i.e., employees have to learn how to use new ICT), techno-uncertainty (i.e., employees' knowledge becomes obsolete due to continuous changes 
in ICT), and techno-insecurity (i.e., employees fear losing their job to others that manage ICT better) (Tarafdar et al. 2011). Later on Ayyagari et al. (2011), reflecting on the misfit between individuals' abilities and technology as per the Person-Environment model of stress (Edwards and Cooper 1990), adapted the previously identified technostress creators into five techno-stressors: work overload (i.e., perception that the assigned job exceeds capabilities or skills), role ambiguity (i.e., lack of information to perform the job), job insecurity (i.e., perception of threat of losing one's job; like techno-insecurity), work-home conflict (i.e., perceived conflict between home and work demands), and invasion of privacy (i.e., perception of a compromised privacy).

Technostress research has used the techno-stressors defined by Tarafdar et al. (2011) or Ayyagari et al. (2011) to analyze their work-related antecedents and consequences. In terms of antecedents, studies have found different organizational environments (e.g., decision centralization; Wang et al. 2008), job characteristics (e.g., job autonomy; Suh \& Lee, 2017), technology features (e.g., complexity; Qi, 2019), and personal characteristics, such as demographics (e.g., age or gender; Marchiori et al. 2019), attitudes (e.g., dispositions to job; Bala and Bhagwatwar 2018), personality (e.g., extraversion; Korzynski et al. 2020), or cultural values (Ma and Turel 2018), to be drivers of technostress. In terms of consequences, technostress produces strain (Galluch et al. 2015; Lee et al. 2016a) and affects negatively other outcomes, such as technology end-user satisfaction (Fuglseth and Søreb $\varnothing$ 2014; Tarafdar et al. 2011; Tu et al. 2008), job satisfaction (Jena 2015; Kumar et al. 2013; Ragu-Nathan et al. 2008), performance (Ioannou and Papazafeiropoulou 2017; Jena 2015; Li and Wang 2021), and organizational commitment (Jena, 2015; Tarafdar et al. 2011). In addition, techno-stressors have been found to hold an ambiguous effect on job productivity: (a positive, significant relationship Hung et al. 2011; a negative, significant relationship Tarafdar et al. 2007, 2011; a non-significant relationship Tu et al. 2005).

Research on technostress has also analyzed inhibitors, a term used to refer to situational factors that may decrease the negative impacts of technostress (Sarabadani et al. 2018). These inhibitors can work either at the individual or organizational levels. Inhibitors at the individual level include literacy facilitation (e.g., training to use the new ICT), technical support provision (e.g., help desk), and user involvement facilitation (e.g., inclusion in the process of ICT implementation) (Ragu-Nathan et al. 2008; Tarafdar et al. 2015). Inhibitors at the organizational level include organizational culture (e.g., innovation openness; RaguNathan et al. 2008; Tarafdar et al. 2015) and job design (e.g., level of autonomy; Suh and Lee 2017). Some of these technostress inhibitors have been shown to either moderate the relationship between techno-stressors and strain or to reduce stress by directly impacting strain. Inhibitors have a positive and direct impact on outcomes, such as end-user satisfaction, job satisfaction, performance, productivity, and organizational commitment (Hung et al. 2011; Jena, 2015; Li and Wang 2021; Tu et al. 2008). Most research studying the antecedents, consequences, and inhibitors of work-related techno-stressors has analyzed their overall effect (e.g., using second-order constructs). However, and as the few studies that have explored their individual effect indicate, such techno-stressors have differential effects on strain and other outcomes and it is worth understanding those individual relationships (Sarabadani et al. 2018).

\subsection{Technostress and teleworking}

Teleworking studies have been mainly conducted with voluntarily adopted teleworking arrangements. Such studies have warned of different individual and environmental factors (i.e., job, organization, family/home, technology) that teleworkers are exposed to due to working from home using ICT (Baruch and Nicholson 1997). For example, studies have analyzed how in the context of teleworking, labor aspects create job demands, such as time pressure, role ambiguity, and role conflict (Sardeshmukh et al. 2012). In addition, the constant development and update of ICTs may force teleworkers to continuously update their own knowledge and skills while dealing with increasingly complex technologies (López-Araujo and Osca Segovia 2008). As such, teleworkers' experience of stress might differ from that of regular workers (Weinert et al. 2015). Teleworkers' high and constant reliance on ICTs makes them susceptible to experience technostress with negative consequences for themselves and the organization (Baruch 2000). This risk was exacerbated for individuals that started working from home forcibly due to the COVID-19 pandemic.

Studies analyzing teleworkers' technostress using the stressor-strain model identified different antecedents and consequences of techno-stressors in this context. In relation to antecedents, ICT features, such as complexity, presenteeism, and pace of change, were found to be antecedents of work overload, invasion of privacy, and role ambiguity (Suh and Lee 2017). Job characteristics, such as isolation, information undersupply, role conflict, and task interdependence, were antecedents of work-home conflict, work overload, invasion of privacy, and role ambiguity (López-Araujo and Osca Segovia 2008; Suh and Lee 2017; Weinert et al. 2015). In relation to inhibitors, having received training to use ICTs helps to reduce technostress in teleworkers (LópezAraujo and Osca Segovia 2008). In relation to consequences, techno-stressors, such as work overload, work-home conflict, invasion of privacy, and role ambiguity, increase strain in teleworkers (Suh and Lee 2017; Weinert et al. 2015). In 
Fig. 1 Research model

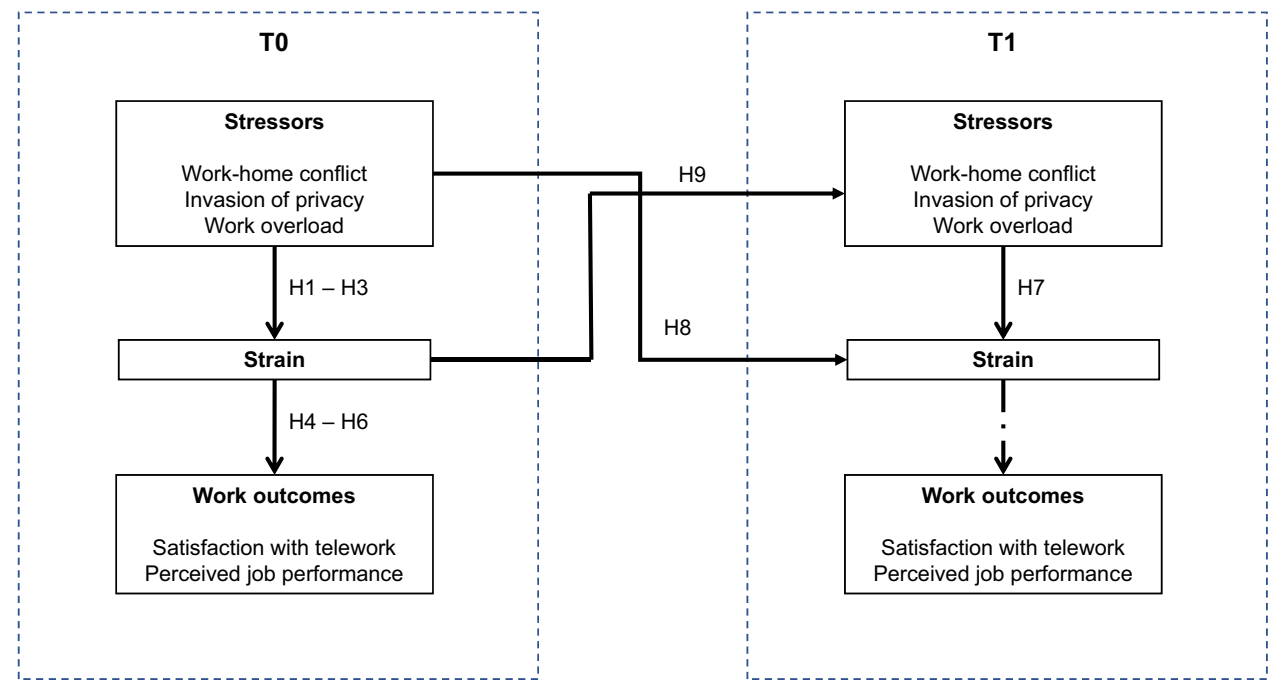

turn, teleworkers' strain has different negative psychological and behavioral outcomes. Psychological outcomes include reduced intention to continue teleworking and a diminished job satisfaction (Suh and Lee 2017; Weinert et al. 2015). Behavioral consequences include lack of initiative, as well as lack of energy to socialize and work (Molino et al. 2020).

\subsection{Technostress effects over time}

According to stress adaptation theory, the effects of stress vary over time (Zapf et al. 1996) depending on the continuity of the stressors (Ford et al. 2014) or individuals' appraisal (Lazarus and Folkman 1984) and adaptation to them (Ritter et al. 2016). A stressor's effect on strain can either return to a baseline level if the stressor stops or people adapt to them (Matthews et al. 2014) or increase if stressors persist or people do not adapt to them (Ford et al. 2014). In the latter situation, three different effects might occur: first, a synchronous effect, which considers the short-term effect where "higher stressors levels are associated with strain at the same point in time" (Ford et al. 2014, p. 10). The appraisal of a particular situation as stressor may be consistent over time when the events that trigger such appraisal are similar and there are contextual similarities (Long and Schutz 1995). Second, a lagged effect, which considers the effects of stress take time develop and emerge due to a cumulative depletion of individual's resources (Ford et al. 2014). The lagged effect measures the extent to which a stressor at one point in time predicts strain experienced later, controlling for baseline strain levels. Third, a reverse causation effect, which considers that strain at one point in time predicts stressors at a later point in time (Ford et al. 2014). The positive relationship between stress and strain creates a negative spiral over time, in which such strain becomes also a stressor in a subsequent moment (de Lange et al. 2004; Sonnentag and Frese 2003; Tucker et al. 2008).

Despite these important insights to understand how the stressor-strain relationships unfold over time, most research on technostress has looked at stressors' effect on strain only at one point at a time, using cross-sectional studies (Benzari et al. 2020). It has been suggested that the stressor-strain process should be examined using longitudinal designs (Kelloway and Francis 2013), as stressors have varying incubation periods before they manifest into strains (Ritter et al. 2016). Examples of longitudinal approaches are studies conducted to analyze technostress in the contexts of social media usage (Maier et al. 2015b), and employees' coping with technostress at different ages (Hauk et al. 2019). As this account indicates, no longitudinal study has analyzed technostress in the context of teleworking.

While teleworking, individuals may face acute technostressors during their workday (e.g., work-family conflicts, work overloads) experiencing momentary negative consequences (e.g., decreased job satisfaction). When these techno-stressors persist over time, individuals may experience a cumulative effect and create chronic stressors. The cumulative effects of technostress have not been analyzed yet and are addressed in the research model presented next.

\section{Research model and hypotheses}

This research proposes a theory-led model to assess teleworkers' technostress evolution over time, as well as its psychological and behavioral effects (see Fig. 1). First, the model is used cross-sectionally to assess the impact of Ayyagari et al.' (2011) techno-stressors relevant in the context of moving to teleworking (work-home conflict, invasion of 


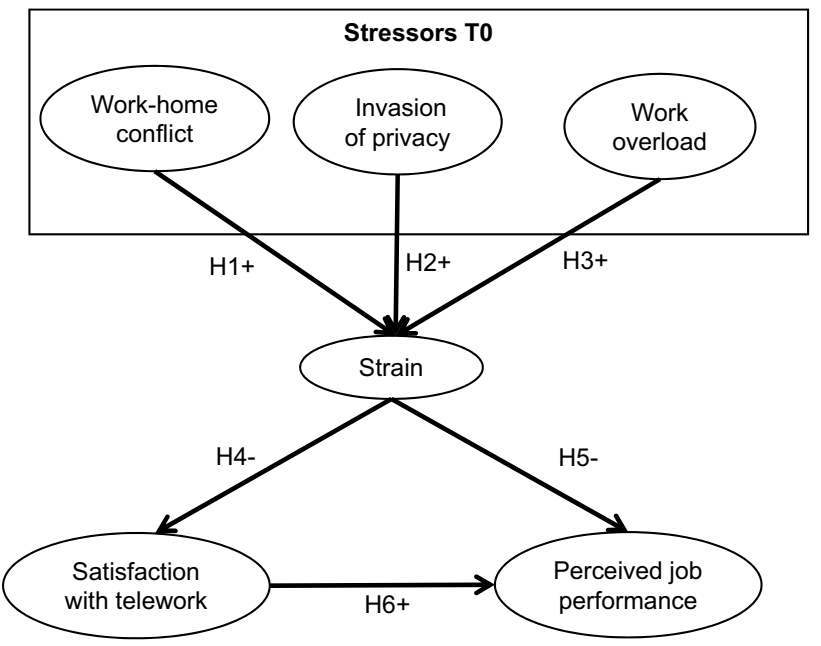

Fig. 2 Consequences of techno-stressors

privacy, and work overload) on strain, as well as how such strain affects satisfaction with telework and perceived job performance (see Fig. 2). Two of the original techno-stressors analyzed by Ayyagari et al.' (2011) are not included in this model: role ambiguity and job insecurity. When moving to teleworking, individuals are relying more on ICT to complete their tasks, but the core of their activities (e.g., inputs, processes, outputs) remains essentially the same. In addition, and even though employees may face the need to learn how to use new ICT, this should not take long enough to make ICT a threat to their job stability. Second, the model is used longitudinally to measure the temporal consequences of technostress experienced by teleworkers (see Fig. 3). Ford et al.'s (2014) three types of technostress effects are assessed: synchronous, lagged, and reverse causation. Next, we describe the different constructs and hypotheses examined in this study.

\subsection{Techno-stressors' effect on strain}

Our first group of hypotheses relates to the effect of three techno-stressors on strain when individuals move to teleworking.

Our first techno-stressor is work-home conflict, which is defined as "the perceived conflict between the demands of work and family" (Ayyagari et al. 2011, p. 834). In the context of teleworking, the work-home boundaries blur (Mann and Holdsworth 2003). Workers occupy a home space using work ICT devices (e.g., computers) and practices (e.g., such as online meetings), which affect the home dynamics (Christensen 1987; Weinert et al. 2015). ICT make individuals spend more time doing job-related
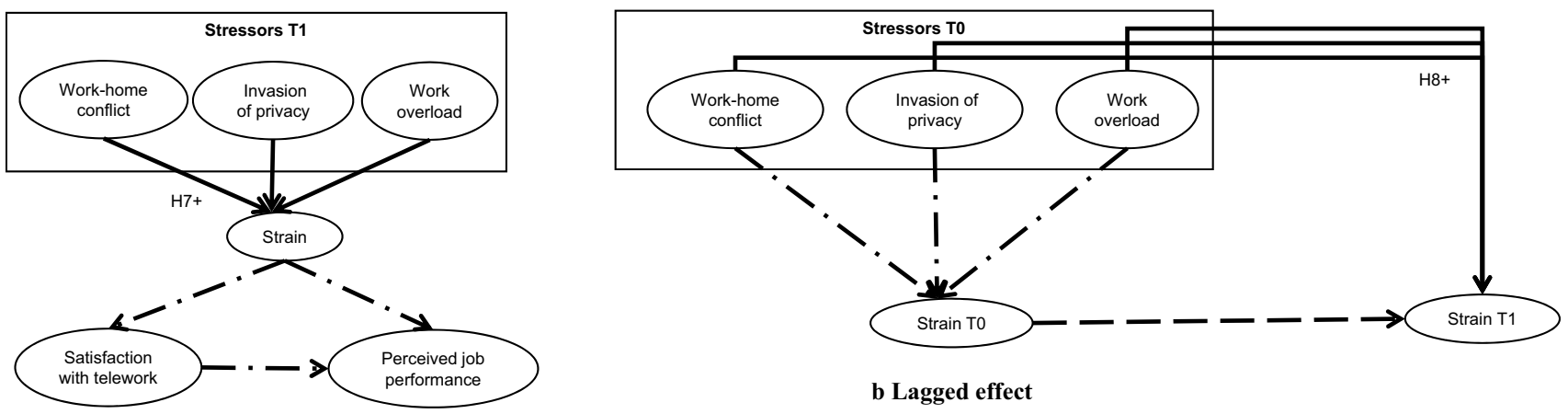

a Synchronous effect

b Lagged effect

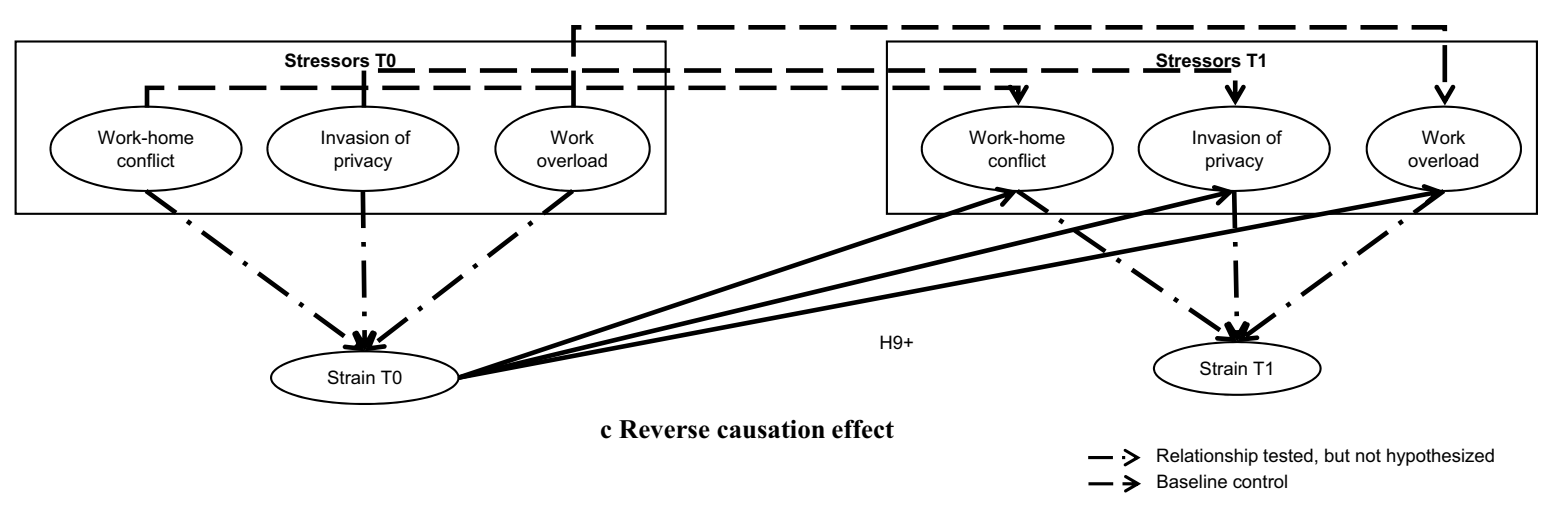

Fig. 3 Temporal effects of technostress 
activities and less time relaxing at home, generating work-home conflict (Lee et al. 2016b). In addition, the household daily activities interfere with the job activities (Haddon and Silverstone 1993). Previous studies have documented the positive effect of work-home conflict on strain (Ayyagari et al. 2011; Lee et al. 2016b). Strain is defined as an emotional negative reaction to encountered techno-stressors (Ayyagari et al. 2011). The effect of work-home conflict on strain has not been analyzed in the teleworking context. We posit this effect holds in this context and therefore hypothesize that:

H1 Work-home conflict is positively related to strain.

The second techno-stressor is invasion of privacy, which is defined as "the perception that an individual's privacy has been compromised" (Ayyagari et al. 2011, p. 834). In general, ICT are perceived as intrusive, making people concerned about privacy and security alternatives (Maier et al. 2015a). Studies in the teleworking context have analyzed invasion of privacy differently, in relation to individuals' perception of infringement on personal time due to their constant ICT connectivity (Suh and Lee 2017). Previous studies have documented the positive effect of both types of invasion of privacy on strain (Ayyagari et al. 2011; Lee et al. 2016a, b; Tu et al. 2005). We contend that this effect will also be observed when individuals move to the teleworking context. As such, we hypothesize that:

H2 Invasion of privacy is positively related to strain.

The third techno-stressor is work overload, and can be defined as "the perception that assigned work exceeds an individual's capability or skill level" (Ayyagari et al. 2011, p. 834). ICT increase the flow of information employees handle throughout their workday and individuals' finite capacity to process and assimilate this information may lead them to experience work overloads (Brown et al. 2014). In the context of telework, organizations adopt various new ICT (e.g., MS Teams, VPN) and change administrative processes (e.g., virtual meetings, digital signatures) to provide employees with continuity of their activities. Teleworkers are required to invest time and effort in not only learning and familiarizing themselves with the new processes, but also dealing with technology issues. These tasks are additional to teleworkers' regular activities. Thus, the constant use of ICT might make teleworkers work longer hours and even during the weekends. Previous studies have documented the positive effect of work overload on strain for employees in general (Galluch et al. 2015; C. Lee et al. 2016a), and in the teleworking context in particular (Suh and Lee 2017). We therefore hypothesize that:
H3 Work overload is positively related to strain.

\subsection{Strain and work-related well-being consequences}

Our second group of hypotheses relates to the consequences of technostress-related strain on employees' well-being. Previous research identifies that work-related stress affects individuals' well-being (Leka et al. 2003). Two work-related variables that influence the decrease of workers' well-being are job satisfaction and perceived job performance (Rothmann 2008). In this study, we analyze how technostress-induced strain affects job satisfaction with telework and perceived job performance when moving to teleworking.

Job satisfaction has been defined as "a pleasurable or positive emotional state resulting from the appraisal of one's job or job experiences" (Locke 1976, p. 1300). Strain has consistently been identified to have negative psychological consequences such as decreased job satisfaction (Jena 2015; Kim et al. 2015; Kumar et al. 2013; Ragu-Nathan et al. 2008). This effect has also been identified in the teleworking context (Suh and Lee 2017). However, in this study, we take a different approach, by analyzing the negative effect of strain on employees' satisfaction with their teleworking experience. Thus, we formulate the following hypothesis:

H4 Strain is negatively related to satisfaction with telework.

Job performance can be defined as "scalable actions, behaviors, and outcomes that employees engage in or bring about that are linked with and contribute to organizational goals" (Viswesvaran and Ones 2000, p. 216). When individuals are experiencing strain, they devote time and energy to cope with stressors rather than to work, which leads to reduced job performance and even burnout (Lord and Kanfer 2002; Tams et al. 2018). Employees may even experience a low performance due to their attempt to avoid executing unfavorable or uncomfortable activities (e.g., ICTbased tasks) (Chang et al. 2009; Lang et al. 2007; Tams et al. 2018). The documented negative effect of strain on job performance (see for example, Ioannou and Papazafeiropoulou 2017; Jena 2015; Tarafdar et al. 2010, 2015) has not been analyzed in the teleworking context. In this study, we propose that strain has a negative effect on employees' perceived job performance while they are teleworking. We therefore hypothesize that:

H5 Strain is negatively related to perceived job performance while teleworking.

Finally, it is well known that attitudes predict corresponding behavior. This is evidenced in the support of the relationship between job satisfaction and performance in 
the organizational behavior literature (Judge et al. 2001; Schleicher et al. 2004; Springer 2011). Although this connection has not been analyzed in the teleworking context, we posit that an employee satisfied with her teleworking experience may also hold positive perceptions about her job performance. Thus, we connect these two constructs in our research model hypothesizing that:

H6 Satisfaction with telework is positively related to perceived job performance while teleworking.

\subsection{Temporal effects of technostress}

Our third group of hypotheses relates to the temporal consequences of technostress experienced by teleworkers. To do this, we elaborate on hypotheses around Ford et al.'s (2014) typology of synchronous, lagged, and reverse causation effects.

The first temporal effect of stress is the synchronous effect, which considers that "higher stressors levels are associated with higher strain at the same point in time" (Ford et al. 2014, p. 10). In the context of teleworking due to a COVID-19 lockdown, it is expected that if the ICTs demands associated to working from home remain stable, the effect of techno-stressors on strain will also be stable over that time. Therefore, it is hypothesized that:

H7 In the context of teleworking, there is a synchronous effect of techno-stressors on strain over time.

The second temporal effect of stress is the lagged effect, which measures the extent to which a stressor at one point in time predicts strain experienced later, controlling for baseline strain levels (Ford et al. 2014). In the context of teleworking due to a COVID-19 lockdown, the continuity of techno-stressors will have a cumulative effect, depleting individuals' resources, affecting not only strain at one point in time (synchronous effect), but also in subsequent moments (lagged effect). Therefore, it is hypothesized that:

H8 In the context of telework, there is a lagged effect of the techno-stressors on strain over time.

The third temporal effect of stress is the reverse causation effect, which considers that the positive relationship between stress and strain creates a negative spiral over time, in which such strain leads to stressors in a subsequent moment (de Lange et al. 2004; Sonnentag and Frese 2003; Tucker et al. 2008). In the context of teleworking due to COVID-19 lockdown, we expect the initial techno-stressors' generated strain will affect subsequent perceived stressors over time, controlling for baseline techno-stressors. Therefore, it is hypothesized that:
H9 In the context of telework, there is a reverse causation effect of strain on techno-stressors over time.

\section{Methodology}

\subsection{Sample and procedure}

The model was tested with working adults that started to telework due to the COVID-19 lockdown implemented in Colombia (South America) on March 24, 2020. Before the lockdown, it was estimated that only $11 \%$ of Colombian companies had implemented telework, and that approximately three million workers had to telework since the beginning of the pandemic (Medina Cartagena 2020). ${ }^{2}$ In addition, it is worth noting that Colombian legislation around teleworking established that companies must provide employees with the necessary IT and furniture (e.g., ergonomic desk and chair) to conduct the tasks, as well as to pay part of employees' utilities (electricity and internet bills) (Función Pública 2017). However, when employees moved to teleworking due to COVID-19, such requirements were not applied as working from home was seen as a temporary and exceptional situation (Unilibre 2020). As such, this context is different from a regular teleworking arrangement, where working hours, work ambiance and costs associated are defined in advance between employers and employees.

Data were collected using an online survey at two points in time (T0 and T1) that were approximately two months apart. The first survey was distributed about a week after the Colombian government established the lockdown measure. Longitudinal stress studies traditionally examine the relationship between stressors (at Time 0) and strain/outcomes (at Time 1) with time lags varying between weeks and months (e.g., Demerouti et al. 2007; Leiter and Durup 1996). The selection of the time interval for longitudinally studies depends on the assessed factors' manifestation over time (Menard 2002). For our study, we selected a lag of two months. After that period, authorities gradually approved some economic sectors to return to in-person work. This time is between the time frames employed in the two longitudinal studies found about technostress: (a) Maier et al. (2015b) collected data on techno-stressors and strain fourteen days after participants stopped using Facebook and on discontinuous use behavior one month after; (b) Hauk et al. (2019) collected data on techno-stressors, coping, and strain in three waves four months apart each.

\footnotetext{
2 During the COVID-19 pandemic, most governments employed lockdowns and companies had to send workers to work from home. Consequently, workers suddenly became full time teleworkers, and some of them are still in this situation.
} 
Participants were recruited using a snowball sampling approach (Gilbert, 1993), starting with researchers' contacts. Snowballing is useful when the target population is hard to reach. In this study, snowball sampling was the only sampling procedure that could be employed at the time as most citizens, including the researchers, were in a strict confinement trying to adapt to teleworking. People with occupations in which teleworking was feasible were contacted via email, Facebook, and WhatsApp.

The survey, at time T0, incorporated the constructs included in the model (Fig. 2) as well as seven control variables (gender, age, education, number of children, experience with ICT for both personal and work-related purposes, work experience, and experience at participants' current job). To contact participants for the second survey, they were asked to report their mobile phone number. At time T1, participants that completed the survey at time T0 were contacted again through WhatsApp or SMS. In addition to the initial constructs, the survey asked them to report whether they were still teleworking and if not, how long they had teleworked. It is important to note that at both times, the survey started with a consent form where aspects related to the study's procedure, length of the survey, compensation, participants' anonymity, and confidentiality of data were established. By clicking on the "Yes" button, they agreed to the information presented and to participate in the study. In terms of confidentiality, the study always tried to maintain participants' anonymity. Even though the mobile number of participants was recorded, no identifying information was collected. Each mobile number was associated to a participant identifier at T0 and used at both T0 and T1 to record participants' responses and analyze the data. Ethics approval was secured before data collection took place, complying with the principles stated in the World Medical Association Declaration of Helsinki (World Health Organization 2001).

At T1, and to compensate participants for answering the two surveys, they were offered a gift card of Netflix (COP\$20,000, approximately USD\$5) or Spotify (COP\$15,000, approximately USD\$4), depending on their preference. To collect the information needed to provide participants with the gift card, they were redirected to a new survey (not connected to the original one) to provide the necessary data (i.e., name, Colombian ID number and address).

\subsection{Measures}

To ensure content validity, this study used previously validated instruments to measure the constructs in the proposed research model after appropriate adaptation to the context of this study. The survey was conducted in Spanish and the items were subjected to double translation to verify the meaning and intent of the items were kept in Spanish. Techno-stressors and strain were measured with scales adapted from Ayyagari et al. (2011). Satisfaction with telework was measured with a scale adapted from Suh and Lee (2017) for teleworking. Finally, perceived performance was measured with a scale adapted from Bal and De Lange (2015). The measurement instruments are included in Appendix 1, Table 1.

\section{Results}

At T0, 154 responses were registered. The records of 11 participants were discarded, as they did not provide demographic information, or the mobile phone number required to contact them for the second survey. At T1, 143 participants were contacted and, after sending a reminder, 96 complete responses were received. It is worth noting that this sample size is adequate to detect a medium effect size $(f=0.15)$ with a power of 0.80 and alpha of 0.05 in linear multiple regression with four predictors, which would require at least 85 participants (Faul et al. 2007). Those 96 cases are used in all analyses presented here.

In terms of age and gender, $71.9 \%$ of participants were between 30 and 49 years old and $60.4 \%$ of participants were female. All participants had at least a college degree and $56.3 \%$ held a master's degree. In terms of number of children, $64.6 \%$ of participants do not have children, $13.5 \%$ have one, $18.8 \%$ have two, and $3.1 \%$ have three children. In terms of teleworking, $42.7 \%$ of participants had had previous teleworking experiences, and from them, $58.5 \%$ had done it for six months or less. In terms of work experience, $63.6 \%$ of participants have worked for at least eleven years and $47.9 \%$ have been at their current companies for five years or less. $76 \%$ of participants worked in private companies, $14.6 \%$ in government agencies, $2.1 \%$ work on their own (without employees), and $7.3 \%$ owned a business. Participants work at different sectors, as follows: education $(38.5 \%)$, services $(20.8 \%)$, industry $(13.5 \%)$, mining and energy (8.3\%), finance $(6.3 \%)$, transportation, communications, and commerce (3.1\% each), construction $(2.1 \%)$, and solidarity (1\%). It is worth mentioning that we collected information on job autonomy (i.e., control over job content, freedom to choose how to perform tasks, setting own schedule to complete tasks; Ahuja et al. 2007) and the results indicate participants had a good level of job autonomy (mean: 3.93 out of 5; SD: 0.93). Finally, $47.9 \%$ of participants have used ICT for personal and work purposes for at least ten years of their lives and $76 \%$ of participants use ICT for work an average of eight or more hours a day. ${ }^{3}$

\footnotetext{
3 To check for respondent bias, participants who took part of the survey at T0 but not at T1 were identified $(n=47)$ and no significant demographic differences were found between this non-respondent group and the sample who took part in both surveys.
} 
Fig. 4 Results-consequences of techno-stressors

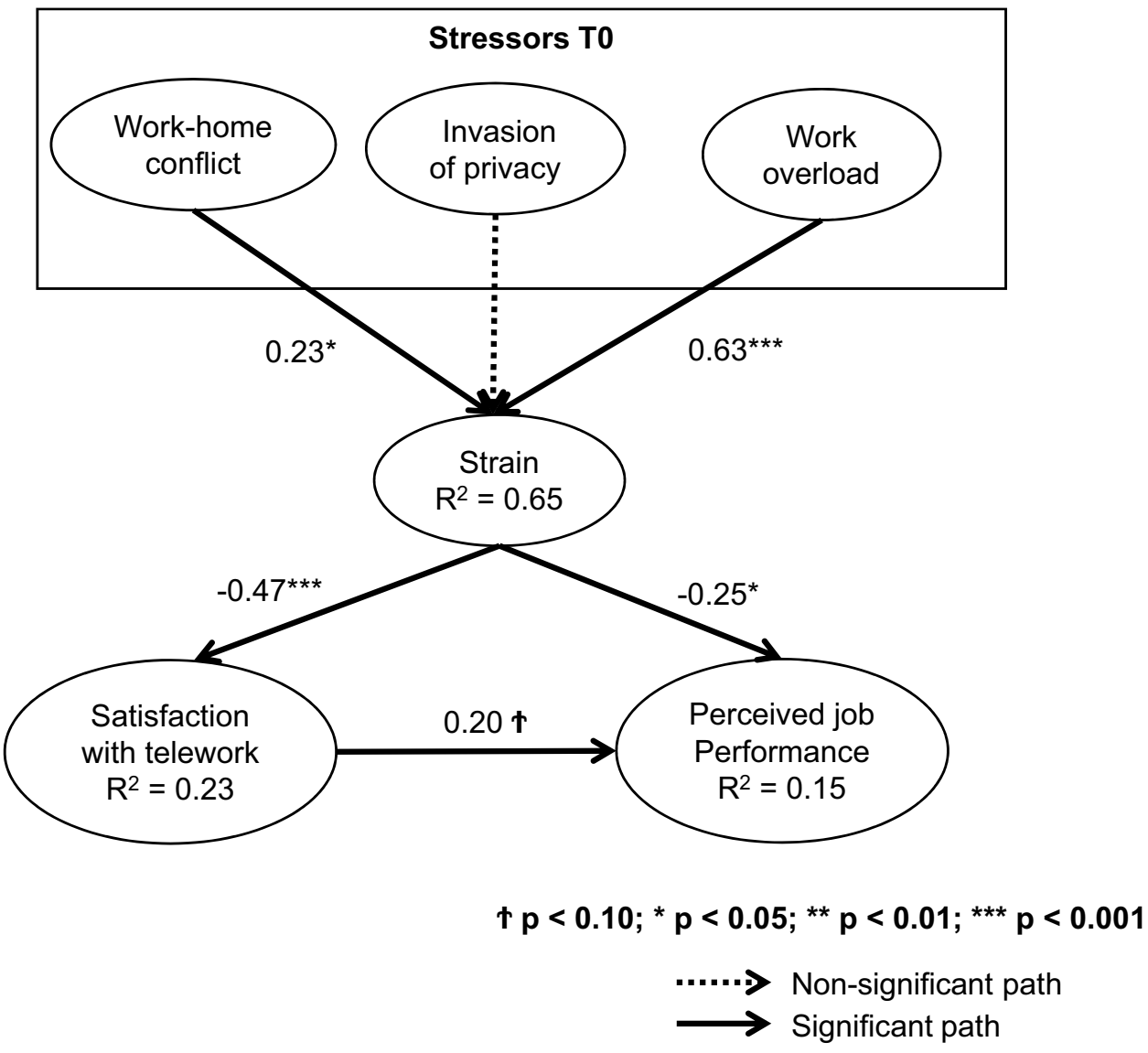

\subsection{Research model validation}

The proposed research model, including cross-sectional and longitudinal relationships, was validated using structural equation modeling (SEM), specifically Partial Least Squares (PLS). PLS is appropriate due to the model's predictive character (Sarstedt et al. 2016) and its lack of assumptions regarding data and residuals distribution (Chin 1998). In addition, PLS path modeling is suitable for longitudinal studies, which are characterized by complex models and small sample sizes (e.g., due to panel attrition) (Roemer 2016). The software used was SmartPLS 3 (Ringle et al. 2015). The evaluation of the research model in PLS includes the assessment of both the measurement and structural models (Chin 2010; Götz et al. 2010). The results presented below follow the reporting guidelines suggested by Hair et al. (2019).

\subsubsection{Measurement model}

The first step of the model validation was the assessment of the measurement models at $\mathrm{T} 0$ and $\mathrm{T} 1$. Item loadings were examined (see Appendix 1, Table 1) and one item from work-home conflict that failed to meet the 0.708 threshold at T0 was removed (Hair et al. 2019). Construct reliability was confirmed with composite reliability (CR) values larger than 0.70 (Hair et al. 2019) for all constructs. Convergent validity was supported with average variance extracted (AVE) values larger than 0.5 (Hair et al. 2019) (see Appendix 1, Table 2). Discriminant validity was assessed by verifying that AVE's square root of a construct was larger than the correlation of that construct with any other construct (Fornell and Larcker 1981). Tables 3 and 4 in Appendix 1 indicate that discriminant validity is met for all constructs in the model. Recent research also recommends the heterotrait-monotrait (HTMT) ratio as a rigorous criterion for discriminant validity, which in this case revealed that all values were below the 0.90 threshold. Inference-based testing also indicated that none of the $95 \%$ confidence intervals for HTMT ratios included the value of 1 . This suggests that all constructs are empirically distinct (Henseler et al. 2015).

\subsubsection{Structural model—cross-sectional design}

After establishing the appropriateness of the measurement model, the structural model at T0 was assessed. There were no collinearity issues among the predictor constructs, as all the VIF values were below three (Hair et al. 2019). As indicated in Fig. 4, the $R^{2}$ obtained for all endogenous constructs was of at least 0.10 (a threshold recommended by Falk and Miller 1992). Results indicate that four out of six hypothesized relationships were supported (H1, H3, H4, and H5). The relationship between job satisfaction and perceived performance (H6) 

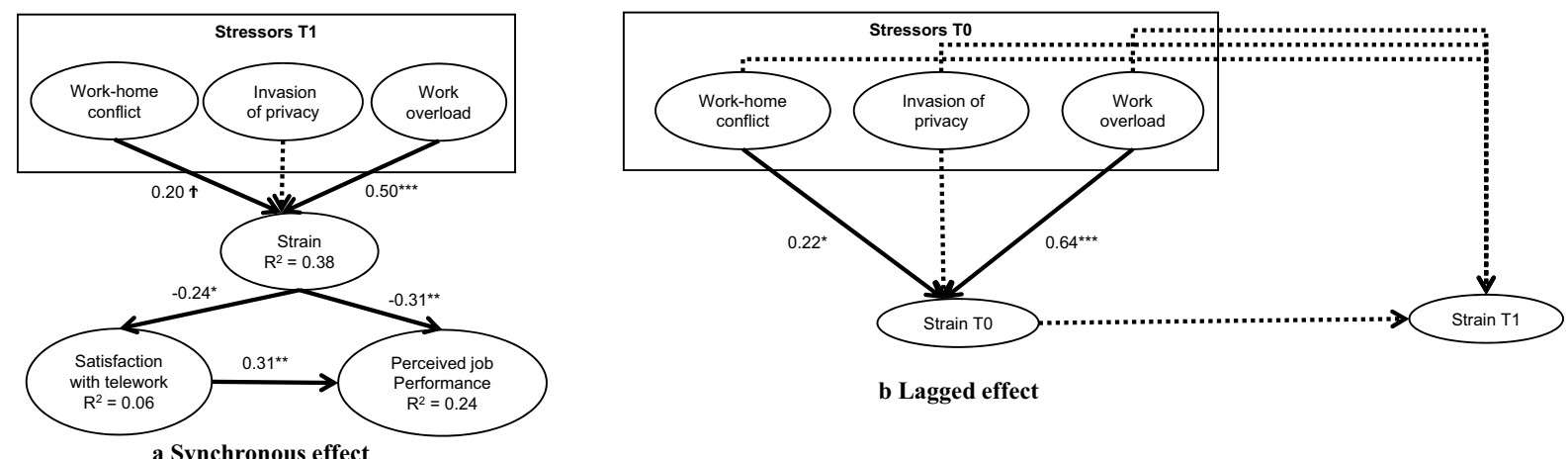

b Lagged effect

a Synchronous effect

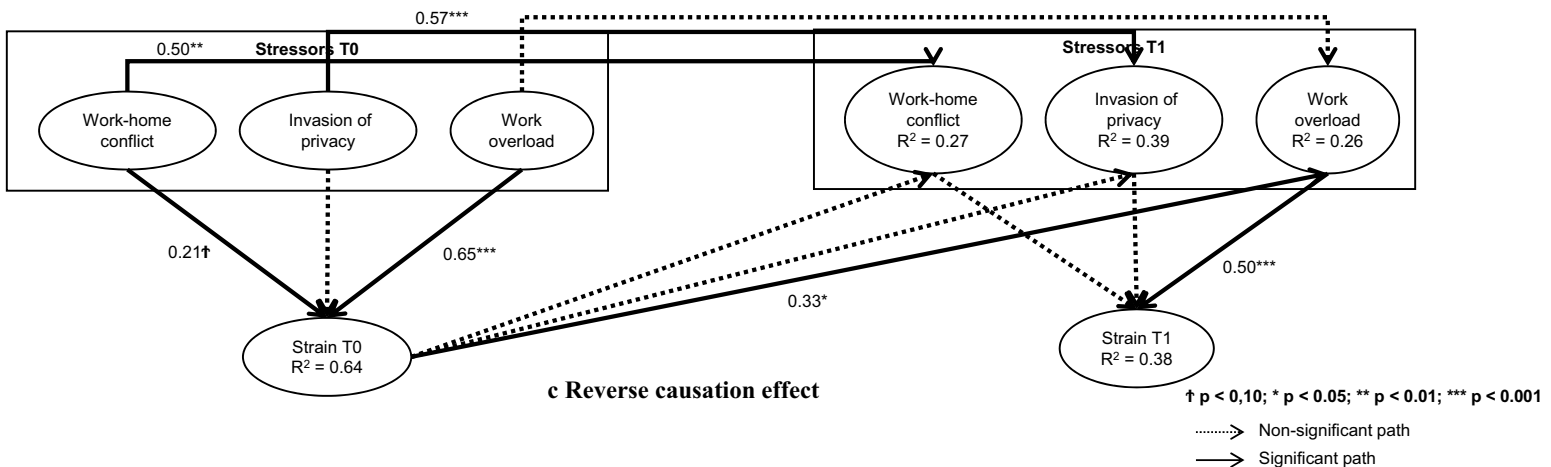

Fig. 5 Results-temporal effects of technostress

was marginally supported. The $Q^{2}$ values obtained for all the endogenous constructs in the model are above zero, indicating that the model has predictive relevance (Chin 2010).

In addition to the constructs included in the model at T0, the following control variables were analyzed to establish their potential influence on the endogenous constructs: gender, age, education, number of children, experience with ICT for both personal and work-related purposes, work experience, and experience at participants' current job. The significance of their paths and effect sizes were examined. However, none of the paths were significant. Thus, control variables did not alter conclusions derived from this study.

\subsubsection{Structural model—longitudinal design}

To examine the effects of technostress over time, three different types of relationships were analyzed (see Fig. 3): (1) the relationships between techno-stressors and strain at $\mathrm{T} 1$ (synchronous effect); (2) the relationships between technostressors at $\mathrm{T} 0$ and strain at $\mathrm{T} 1$, controlling for strain at $\mathrm{T} 0$ (lagged effect); and (3) the relationships between strain at T0 and techno-stressors at T1, controlling for techno-stressors at T0 (reverse causation effect). As indicated in Fig. 5a, the results for the synchronous effects show that work overload is the only antecedent of strain that remains significant at T1 (work-home conflict was marginally supported). As such, H7 is partially supported. Strain is still a negative determinant of job satisfaction and perceived performance and the positive relationship between job satisfaction and perceived performance is supported at T1. As denoted in Fig. 5b, results indicate the lagged effect is not present (H8 is thus not supported). Finally, the results for the reverse causation effect shown in Fig. $5 \mathrm{c}$ indicate that strain at T0 has a positive and significant impact on work overload at $\mathrm{T} 1$ and that two techno-stressors at $\mathrm{T} 0$ increase the techno-stressors at $\mathrm{T} 1$ (invasion of privacy and work-home conflict). Thus, H9 is partially supported.

\section{Discussion}

This study posed the following research question: What are the temporal effects of teleworkers' technostress? To address this question, a theoretical model was proposed including three sets of hypotheses: the effect of three techno-stressors (work-home conflict, invasion of privacy, and work overload) on strain (H1-H3), the work outcomes of strain (satisfaction with telework and perceived performance; H4-H6), and the different temporal effects (synchronous, lagged, reverse causation) of technostress (H7-H9). These hypotheses were empirically tested with a longitudinal study at two points in time (a week after teleworking started-T0- and two months after-T1) with a group of individuals $(n=96)$ that moved to teleworking due to a COVID-19 lockdown. Data were analyzed using SmartPLS 3, and results indicate 
that four hypotheses were supported $(\mathrm{H} 1, \mathrm{H} 3, \mathrm{H} 4$, and $\mathrm{H} 5)$, two were partially supported (H7 and H9), one was marginally supported (H6), and two were not supported (H2 and H8). In this section, we provide a detailed explanation of these results, discussing how they complement and extend previous research on technostress in the context of teleworking, as well as their implications for practice.

First, consistent with prior research about techno-stressors' negative effect on teleworkers' strain (López-Araujo and Osca Segovia 2008; Suh and Lee 2017; Weinert et al. 2015), evidence supports that work-home conflict (H1) and work overload (H3) have significant immediate effects on teleworkers' strain. The effect of invasion of privacy on strain (H2) was not supported. A potential explanation for this situation is that when individuals moved to telework, they relied on traditional commercial applications (e.g., Zoom, Skype), which may have reduced their concerns of privacy violations (i.e., they were using well-known applications they trusted) and of being monitored by their companies (i.e., they were using third-party software).

Second, consistent with previous studies about the effect of strain on job satisfaction for teleworkers (López-Araujo and Osca Segovia 2008; Suh and Lee 2017), evidence supports that strain reduces employees' satisfaction with telework $(\mathrm{H} 4)$. In a similar way, strain was found to directly reduce teleworkers' perceived job performance (H5). Finally, consistent with studies in other contexts (Judge et al. 2001), results marginally support a positive relationship between employees' satisfaction with telework and their perceived job performance (H6).

Third, results partially support a synchronous effect of techno-stressors on strain (H7). In each period, teleworkers experienced work overload with an immediate impact on strain. There was not a synchronous effect of invasion of privacy on strain, which suggests that the explanation outlined above (i.e., the use of third-party applications reduced participants' concerns of privacy violations and of being monitored) still holds through time. The synchronous effect of work-home conflict on strain was marginally supported. This result may be explained by considering that $64.6 \%$ of participants do not have children: for such participants, it might have been easier to balance home and ICT-related demands after two months. Evidence does not support the lagged effect of any techno-stressor on strain (H8). A possible explanation is that as individuals continue experiencing these techno-stressors over time, the effects of such technostressors do not take time to develop but might rather occur immediately at each period (i.e., synchronous effect). Finally, evidence partially supports there is a reverse causation effect of strain on techno-stressors (H9). Prior experience of strain was not only an outcome, but also a determinant of subsequent higher levels of work overload. A possible explanation is that teleworkers were not able to fully adapt to the strain generated by work-home conflict and work overload at $\mathrm{T} 0$, and such strain generated a vicious cycle affecting work overload at T1. Next, we discuss implications of these results for theory and practice.

\subsection{Theoretical implications}

This study results provide several theoretical contributions, offering a more comprehensive understanding about workrelated technostress, specifically in the context of teleworkers. First, findings illustrate the dynamics between techno-stressors and strain for teleworkers over time. The result of the synchronous effect is consistent with studies about humans' ability to adapt to stressful events (Ritter et al. 2016). In this case, some techno-stressors have an immediate effect on strain (i.e., workhome conflict and work overload), while for others (i.e., invasion of privacy) teleworkers might be able to adapt to them. The identified reverse causation effect accounts for technostress' effect cycle, in which teleworkers' current strain shapes future technostressors and related strain. This is consistent with the notion of a loss spiral, where stress makes employees lose resources (e.g., energy) needed to deal with their job demands and further sources of stress (Hobfoll 2001). These results (1) lend support to stress adaptation theory (Zapf et al. 1996) in relation to the effects of stressors' continuity or individuals' adaptation (Ford et al. 2014; Ritter et al. 2016); (2) extend the majority of studies on work-related technostress, which focused on its effect at one point in time (for a summary, see Benzari et al. 2020); and (3) broaden the analysis to the teleworking context, where research has analyzed only the path in which techno-stressors increase employees' strain levels (Suh and Lee 2017).

Second, the proposed model identifies two negative workrelated outcomes of teleworkers' technostress: one psychological (satisfaction with telework) and one behavioral (perceived job performance), as well as the relationship between them. There results extend previous studies on teleworkers' technostress that have analyzed either psychological (i.e., job satisfaction; López-Araujo and Osca Segovia 2008; Suh and Lee 2017) or behavioral outcomes (e.g., intention to continue teleworking Weinert et al. 2015). Results show that strain derived from technostress has a negative effect on employees' satisfaction with telework, as well as on their perceived job performance. Moreover, the relationship between satisfaction with telework and perceived job performance highlights the need to analyze these technostress outcomes jointly.

Third, this study provides a context-specific theory development of technostress in teleworking during the COVID-19 pandemic. Companies adopted teleworking as a safety practice to guarantee work continuity, forced by external circumstances (Belzunegui-Eraso and Erro-Garcés 2020). In most of the studies conducted in technostress for teleworkers, participants worked at companies that had adopted long-term teleworking programs and where individuals allotted a different amount of time to teleworking (e.g., number of days per week, a percentage of the workday) (López-Araujo and Osca Segovia 2008; Suh and Lee 2017; Weinert et al. 2015). In this study, the rapid adoption of this work arrangement, in addition to other stressful factors linked to the pandemic (e.g., isolation, fear of contagion,) put workers 
in a stressful, vulnerable situation. Results extend previous studies that analyzed this phenomenon using techno-stress creators (Molino et al. 2020), using techno-stressors that reflect the misfit between individuals' abilities and technology and by analyzing techno-stressors' evolving nature and job outcomes. Longitudinal studies and monitoring practices are essential to understand the evolution of technostress in a pandemic situation that will prolong remote working for an extended period (e.g., more than one year).

\subsection{Practical implications}

Work has an important role in promoting individuals' wellbeing, but it can also deteriorate it when work leads to stress (NICE 2009). This study's findings provide noteworthy practical implications for organizations and policy-makers aiming to reduce work-related stress. These implications complement standards that international organizations have established around workers' occupational health and safety management (e.g., ISO 45001/45003), especially during the pandemic (e.g., ISO/PAS 45005).

First, occupational health and safety management standards around working during COVID-19 (ISO/PAS 45005) remark that organizations should establish processes to manage the impact of the pandemic on workers' psychological health and well-being. The results of this study indicate that there are two sources of technostress when individuals move forcibly and suddenly to teleworking: work-home conflict and work overload. Considering the negative consequences of those techno-stressors (i.e., strain, reduced satisfaction with telework and reduced perceptions of performance), companies might consider establishing policies and rules around teleworking (e.g., hours and media used to contact employees) to reduce the additional pressure that constant connectivity and use of ICTs impose on employees.

Second, occupational health and safety management standards around workers' psychological health (ISO 45001/45003) remark the need to identify strain impairing effects, workers' temporal pattern of recovery and the means to achieve this. This study's results on the reverse causation effect indicate that previous experience of strain derived from technostress increases perceptions of work overload in subsequent periods. This suggests that before establishing teleworking programs, organizations should consider employees' occupational history with teleworking to account for past exposures to techno-stressors that may have implications for future experiences of technostress. Then, while teleworking, longitudinal evaluations of technostress can be implemented to identify changes over time. The model of this study could be the basis for such evaluation. Results on the synchronous effect of work overload on strain indicates workers may not be able to cope properly to reduce technostress effects in subsequent periods. This suggests organizations might focus on providing employees with alternatives to help them deal with these technostressors. For example, giving teleworkers extended breaks from stressors (e.g., one day a week without virtual meetings) may allow them to replenish their resources and reduce strain over time (Ford et al. 2014). Such alternatives might not only decrease teleworkers' strain and negative outcomes in each period, but also be useful to reduce the reverse causation effect over time.

\subsection{Limitations and future studies}

The first limitation of this study is that the model analyzes just a specific type of teleworking: home-based. In addition, we selected an extreme context to elucidate our findings (a COVID-19 lockdown). In this context, workers moved to telework suddenly and forcibly, which created a more challenging work environment. Eckhardt et al. (2019) pointed out that workers must have mental, technological, and relational readiness to face teleworking. Future studies can analyze other contexts when companies decide to move their employees to teleworking, as well as the location of employees in other settings (e.g., shared workspaces, working from public places, such as cafés or libraries).

A second limitation is that our sample is composed mostly of highly educated participants (i.e., all participants had at least a college degree), with no kids. However, it is worth noting that individuals with higher levels of education are more likely than those with lower levels of education to be teleworking from home (Marshall et al. 2021). Future studies may analyze teleworking environments with a sample of individuals with a more diverse educational background and family composition.

A third limitation is that the evaluation of constructs in the theoretical model involved participants' self-reported measures. Previous research in different areas of human behavior indicated that there is overestimation or underestimation of actual behaviors in this type of assessment (Junco 2013). Some studies have also found discrepancies between self-reported and other-reported behaviors (see for example, Chao and Lam 2011 on responsible environmental behaviors). Moreover, differences or conflicts between beliefs and behaviors may lead to unethical situations (Vanderhaegen 2021). However, it is worth pointing out that research on productivity and performance indicates that (1) self-reported measures have a generic orientation across demographics and job demographics and thus, they facilitate comparisons across occupations (Allen and Bunn 2003); and (2) objective and subjective measures of performance are positively correlated and are predicted by similar independent variables (Bommer et al. 1995; Wall et al. 2004).

A fourth and final limitation is that our longitudinal study had only two iterations carried out two months apart. Future studies may collect measures with different iterations over an extended period. In addition, future research can explore the effect of both organizations' interventions and teleworkers' coping strategies to counter techno-stressors. It would be valuable to analyze cognitive, emotional, and behavioral adaption to techno-stressors over time to extend the results obtained in this study. 


\section{Conclusion}

Cognition, Technology and Work journal discusses how human cognition is affected by work and working conditions. COVID-19 forced organizations to make their employees full-time teleworkers, having to develop their job activities from home. This new working environment placed new demands on employees, which in some cases exceeded their capabilities and made them experience technostress. This study analyzed how three techno-stressors (work overload, work-family conflict, and invasion of privacy) generated strain on teleworkers, which affected their workrelated well-being in terms of the perceptions of satisfaction with

Table 1 Measurement instruments and items loadings- $-\mathrm{T} 0$ and T1

\begin{tabular}{|c|c|c|c|c|}
\hline Construct (acronym; Source) & Item descriptor & Item & Loading T0 & Loading T1 \\
\hline \multicolumn{5}{|l|}{ Stressors } \\
\hline \multirow[t]{3}{*}{$\begin{array}{l}\text { Work-home conflict (WHC; Ayyagari et al. } \\
\text { 2011) }\end{array}$} & WHC1 & $\begin{array}{l}\text { Using ICTs blurs boundaries between my job } \\
\text { and my home life } \\
\text { Item dropped due to low loading }\end{array}$ & 0.53 & 0.83 \\
\hline & WHC2 & $\begin{array}{l}\text { Using ICTs for work-related responsibilities cre- } \\
\text { ates conflicts with my home responsibilities }\end{array}$ & 0.92 & 0.92 \\
\hline & WHC3 & $\begin{array}{l}\text { I do not get everything done at home because I } \\
\text { find myself completing job-related work due } \\
\text { to ICTs }\end{array}$ & 0.88 & 0.87 \\
\hline \multirow[t]{4}{*}{ Invasion of privacy (IOP; Ayyagari et al. 2011) } & IOP1 & $\begin{array}{l}\text { I feel uncomfortable that my use of ICTs can be } \\
\text { easily monitored }\end{array}$ & 0.85 & 0.90 \\
\hline & IOP2 & $\begin{array}{l}\text { I feel my privacy can be compromised because } \\
\text { my activities using ICTs can be traced }\end{array}$ & 0.92 & 0.92 \\
\hline & IOP3 & $\begin{array}{l}\text { I feel my employer could violate my privacy by } \\
\text { tracking my activities using ICTs }\end{array}$ & 0.93 & 0.90 \\
\hline & IOP4 & $\begin{array}{l}\text { I feel that my use of ICTs makes it easier to } \\
\text { invade my privacy }\end{array}$ & 0.89 & 0.94 \\
\hline \multirow[t]{3}{*}{ Work overload (WO; Ayyagari et al. 2011) } & WO1 & $\begin{array}{l}\text { ICTs create many more requests, problems, or } \\
\text { complaints in my job than I would otherwise } \\
\text { experience }\end{array}$ & 0.73 & 0.73 \\
\hline & WO2 & I feel busy or rushed due to ICTs & 0.92 & 0.93 \\
\hline & WO3 & I feel pressured due to ICTs & 0.93 & 0.94 \\
\hline \multicolumn{5}{|l|}{ Outcomes } \\
\hline \multirow[t]{3}{*}{ Strain (ST; Ayyagari et al. 2011) } & ST1 & $\begin{array}{l}\text { I feel drained from activities that require me to } \\
\text { use ICTs }\end{array}$ & 0.95 & 0.87 \\
\hline & ST2 & I feel tired from my ICT activities & 0.96 & 0.94 \\
\hline & ST3 & Working all day with ICTs is a strain for me & 0.88 & 0.90 \\
\hline \multirow[t]{3}{*}{$\begin{array}{l}\text { Satisfaction with telework (SWT; Suh and Lee } \\
\text { 2017) }\end{array}$} & SWT1 & $\begin{array}{l}\text { How do you feel about your overall experience } \\
\text { of telework? } \\
\text { Satisfied }\end{array}$ & 0.90 & 0.94 \\
\hline & SWT2 & Pleased & 0.96 & 0.92 \\
\hline & SWT3 & Contented & 0.94 & 0.94 \\
\hline \multirow[t]{3}{*}{$\begin{array}{l}\text { Perceived performance (PP; Bal and de Lange } \\
\text { 2015) }\end{array}$} & PP1 & $\begin{array}{l}\text { How would you rate your current job perfor- } \\
\text { mance? }\end{array}$ & 0.83 & 0.88 \\
\hline & PP2 & $\begin{array}{l}\text { Think about your most recent assessment of your } \\
\text { job performance or the most recent time you } \\
\text { received feedback from your supervisor. How } \\
\text { do you think your supervisor would rate your } \\
\text { performance? }\end{array}$ & 0.78 & 0.87 \\
\hline & PP3 & $\begin{array}{l}\text { How would you rate your performance as a work } \\
\text { team member? }\end{array}$ & 0.85 & 0.89 \\
\hline
\end{tabular}

telework and perceived job performance. In addition, this study explored the consequences of technostress over time, an aspect not previously analyzed in the literature. Teleworkers experience strain derived from technostress that increases their work overload at a subsequent time, generating a loss spiral. Given the large number of organizations that developed teleworking around the world due to COVID-19 and are currently trying to determine whether to continue with this practice after the pandemic, this study makes a timely contribution to both research and practice.

\section{Appendix 1}

See Tables 1, 2, 3 and 4. 
Table 2 Composite reliability (CR) and average variance extracted (AVE) — $\mathrm{T} 0$ and $\mathrm{T} 1$
Table 3 Construct correlations- $\mathrm{T} 0$

Table 4 Construct correlations-T1

\begin{tabular}{|c|c|c|c|c|}
\hline \multirow[t]{2}{*}{ Construct } & \multicolumn{2}{|l|}{ T0 } & \multicolumn{2}{|l|}{ T1 } \\
\hline & CR & AVE & $\mathrm{CR}$ & AVE \\
\hline Invasion of privacy (IOP) & 0.95 & 0.81 & 0.95 & 0.84 \\
\hline Satisfaction with telework (SWT) & 0.95 & 0.87 & 0.95 & 0.87 \\
\hline Perceived performance (PP) & 0.86 & 0.68 & 0.91 & 0.77 \\
\hline Strain (ST) & 0.95 & 0.86 & 0.93 & 0.82 \\
\hline Work overload (WO) & 0.90 & 0.75 & 0.90 & 0.76 \\
\hline Work-home conflict (WHC) & 0.91 & 0.84 & 0.91 & 0.77 \\
\hline
\end{tabular}

\begin{tabular}{lcccccc}
\hline & IOP & SWT & PP & ST & WO & WHC \\
\hline Invasion of privacy (IOP) & $\mathbf{0 . 9}$ & & & & & \\
Satisfaction with telework (SWT) & -0.37 & $\mathbf{0 . 9 3}$ & & & & \\
Perceived performance (PP) & -0.27 & 0.32 & $\mathbf{0 . 8 2}$ & & & \\
Strain (ST) & 0.4 & -0.47 & -0.35 & $\mathbf{0 . 9 3}$ & & \\
Work overload (WO) & 0.47 & -0.36 & -0.38 & 0.79 & $\mathbf{0 . 8 7}$ & \\
Work-home conflict (WHC) & 0.53 & -0.35 & -0.44 & 0.69 & 0.74 & $\mathbf{0 . 9 2}$
\end{tabular}

Items in bold correspond to the square root of AVE values

\begin{tabular}{lrrrrrr}
\hline & \multicolumn{1}{c}{ IOP } & SWT & PP & ST & WO & WHC \\
\hline Invasion of privacy (IOP) & $\mathbf{0 . 9 2}$ & & & & & \\
Satisfaction with telework (SWT) & -0.26 & $\mathbf{0 . 9 3}$ & & & & \\
Perceived performance (PP) & -0.39 & 0.38 & $\mathbf{0 . 8 8}$ & & & \\
Strain (ST) & 0.33 & -0.24 & -0.39 & $\mathbf{0 . 9 0}$ & & \\
Work overload (WO) & 0.56 & -0.33 & -0.43 & 0.60 & $\mathbf{0 . 8 7}$ & \\
Work-home conflict (WHC) & 0.47 & -0.17 & -0.37 & 0.49 & 0.62 & $\mathbf{0 . 8 8}$ \\
\hline
\end{tabular}

Items in bold correspond to the square root of AVE values
Funding The authors did not receive support from any organization for the submitted work.

Availability of data and material Data are available from the corresponding author upon reasonable request.

Code availability Not applicable.

\section{Declarations}

Conflict of interest The authors have no relevant financial or non-financial interests to disclose. Sonia Camacho declares she has no conflict of interest. Andrés Barrios declares he has no conflict of interest.

Ethical approval All procedures performed in studies involving human participants were in accordance with the ethical standards of the institutional and/or national research committee and with the 1964 Helsinki declaration and its later amendments or comparable ethical standards.
Informed consent Informed consent was obtained from all individual participants included in the study.

\section{References}

Ahuja MK, Chudoba KM, Kacmar CJ, Harrison McKnight D, George JF (2007) It road warriors: balancing work-family conflict, job autonomy, and work overload to mitigate turnover intentions. MIS Quart Manag Inf Syst 31(1):1-17. https://doi.org/10.2307/ 25148778

Allen HM, Bunn WB (2003) Validating self-reported measures of productivity at work: a case for their credibility in a heavy manufacturing setting. J Occup Environ Med 45(9):926-940. https://doi. org/10.1097/01.JOM.0000090467.58809.5C

Ayyagari R, Grover V, Purvis R (2011) Technostress: technological antecedents and implications. MIS Quart Manag Inf Syst 35(4):831-858. https://doi.org/10.2307/41409963

Bailey DE, Kurland NB (2002) A review of telework research: findings, new directions, and lessons for the study of modern work. 
J Organ Behav 23(Spec. Iss.):383-400. https://doi.org/10.1002/ job. 144

Bal PM, de Lange AH (2015) From flexibility human resource management to employee engagement and perceived job performance across the lifespan: a multisample study. J Occup Organ Psychol 88(1):126-154. https://doi.org/10.1111/joop.12082

Bala H, Bhagwatwar A (2018) Employee dispositions to job and organization as antecedents and consequences of information systems use. Inf Syst J 28(4):650-683. https://doi.org/10.1111/isj.12152

Baruch Y (2000) Teleworking: Benefits and pitfalls as perceived by professionals and managers. N Technol Work Employ 15(1):3449. https://doi.org/10.1111/1468-005X.00063

Baruch Y, Nicholson N (1997) Home, sweet work: requirements for effective home working. J Gen Manag 23(2):15-30. https://doi. org/10.1177/030630709702300202

Belzunegui-Eraso A, Erro-Garcés A (2020) Teleworking in the context of the Covid-19 crisis. Sustainability 12(9):3662. https://doi.org/ $10.3390 /$ su12093662

Benzari A, Khedhaouria A, Torrès O (2020) The rise of technostress: a literature review from 1984 until 2018. ECIS 2020 Research Papers. https://aisel.aisnet.org/ecis2020_rp/140

Bommer WH, Johnson JL, Rich GA, Podsakoff PM, Mackenzie SB (1995) On the interchangeability of objective and subjective measures of employee performance: a meta-analysis. Pers Psychol 48(3):587-605. https://doi.org/10.1111/j.1744-6570.1995. tb01772.x

Brown R, Duck J, Jimmieson N (2014) E-mail in the workplace: the role of stress appraisals and normative response pressure in the relationship between E-mail stressors and employee strain. Int J Stress Manag 21(4):325-347. https://doi.org/10.1037/a0037 464

Burns RA, Butterworth P, Anstey KJ (2016) An examination of the long-term impact of job strain on mental health and wellbeing over a 12-year period. Soc Psychiatry Psychiatr Epidemiol 51(5):725-733. https://doi.org/10.1007/S00127-016-1192-9

Chang CH, Rosen C, Levy P (2009) The relationship between perceptions of organizational politics and employee attitudes, strain, and behavior: a meta-analytic examination. Acad Manag J 52(4):779-801. https://doi.org/10.5465/AMJ.2009.43670894

Chao YL, Lam SP (2011) Measuring responsible environmental behavior: self-reported and other-reported measures and their differences in testing a behavioral model. Environ Behav 43(1):53-71. https://doi.org/10.1177/0013916509350849

Chesley N (2014) Information and communication technology use, work intensification and employee strain and distress. Work Employ Soc 28(4):589-610. https://doi.org/10.1177/09500 17013500112

Chin WW (1998) The partial least squares approach to structural equation modeling. Mod Methods Bus Res 295(2):295-336

Chin WW (2010) How to write up and report PLS analyses. In: Vinzi VE, Chin WW, Henseler J, Wang H (eds) Handbook of partial least squares. Springer, Berlin, pp 655-690

Christensen KE (1987) Impacts of computer-mediated homebased work on women and their families. Off Technol People 3(3):211-230. https://doi.org/10.1108/eb022649

Cox T, Griffiths A (2010) Work-related stress: a theoretical perspective. In: Leka S, Houdmont J (eds) Occupational health psychology. Wiley Blackwell, Hoboken, pp 31-56

de Lange AH, Taris TW, Kompier MAJ, Houtman ILD, Bongers PM (2004) The relationships between work characteristics and mental health: examining normal, reversed and reciprocal relationships in a 4-wave study. Work Stress 18(2):149-166. https://doi.org/10.1080/02678370412331270860

Demerouti E, Taris TW, Bakker AB (2007) Need for recovery, homework interference and performance: is lack of concentration the link? J Vocat Behav 71(2):204-220. https://doi.org/10.1016/j. jvb.2007.06.002

Dollard MF, Winefield HR, Winefield AH, de Jonge J (2000) Psychosocial job strain and productivity in human service workers: a test of the demand-control-support model. J Occup Organ Psychol 73(4):501-510. https://doi.org/10.1348/0963179001 67182

Eckhardt A, Endter F, Giordano A, Somers P (2019) Three stages to a virtual workforce. MIS Quart Exec 18(1). https://aisel.aisnet. org/misqe/vol18/iss $1 / 5$

Edwards JR, Cooper CL (1990) The person-environment fit approach to stress: recurring problems and some suggested solutions. J Organ Behav 11(4):293-307

Estrada-Muñoz C, Vega-Muñoz A, Castillo D, Müller-Pérez S, BoadaGrau J (2021) Technostress of Chilean teachers in the context of the COVID-19 pandemic and teleworking. Int J Environ Res Public Health 18(10):5458. https://doi.org/10.3390/ijerph18105458

Falk RF, Miller NB (1992) A primer for soft modeling. University of Akron Press, Akron

Faul F, Erdfelder E, Lang A-G, Buchner A (2007) G* Power 3: a flexible statistical power analysis program for the social, behavioral, and biomedical sciences. Behav Res Methods 39(2):175-191

Ford MT, Matthews RA, Wooldridge JD, Mishra V, Kakar UM, Strahan SR (2014) How do occupational stressor-strain effects vary with time? A review and meta-analysis of the relevance of time lags in longitudinal studies. Work Stress 28(1):9-30. https://doi.org/ 10.1080/02678373.2013.877096

Fornell C, Larcker DF (1981) Evaluating structural equation models with unobservable variables and measurement error. J Mark Res 18(1):39-50

Fuglseth AM, Sørebø Ø (2014) The effects of technostress within the context of employee use of ICT. Comput Hum Behav 40:161170. https://doi.org/10.1016/j.chb.2014.07.040

Función Pública (2017) Libro blanco-El ABC del teletrabajo en Colombia. https://www.funcionpublica.gov.co/eva/red/publi caciones/documento-funcional----el-libro-blanco-el-abc-del-telet rabajo-en-colombia

Galluch PS, Grover V, Thatcher JB (2015) Interrupting the workplace: examining stressors in an information technology context. J Assoc Inf Syst 16(1):1-47. https://doi.org/10.17705/1jais.00387

Gilbert N (1993) Researching social life. Sage, Thousand Oaks

Götz O, Liehr-Gobbers K, Krafft M (2010) Evaluation of structural equation models using the partial least squares (PLS) approach. Handbook of partial least squares. Springer, Berlin, pp 691-711. https://doi.org/10.1007/978-3-540-32827-8_30

Haddon L, Silverstone R (1993) Teleworking in the 1990s-a view from the home. http://eprints.1se.ac.uk/62467/1/Teleworking in_the.pdf

Hair JF, Risher JJ, Sarstedt M, Ringle CM (2019) When to use and how to report the results of PLS-SEM. Eur Bus Rev 31(1):2-24. https://doi.org/10.1108/EBR-11-2018-0203

Hauk N, Göritz AS, Krumm S (2019) The mediating role of coping behavior on the age-technostress relationship: a longitudinal multilevel mediation model. PLoS ONE 14(3):e0213349. https://doi. org/10.1371/journal.pone.0213349

Henseler J, Ringle CM, Sarstedt M (2015) A new criterion for assessing discriminant validity in variance-based structural equation modeling. J Acad Mark Sci 43(1):115-135

Hobfoll SE (2001) The influence of culture, community, and the nested-self in the stress process: advancing conservation of resources theory. Appl Psychol 50(3):337-421. https://doi.org/ 10.1111/1464-0597.00062

Hung W-H, Chang L-M, Lin C-H (2011) Managing the risk of overusing mobile phones in the working environment: a study of ubiquitous technostress. In: PACIS 2011 proceedings 
International Labour Organization (2020) ILO monitor: Covid-19 and the world of work, 2nd ed. https://gisanddata.maps.arcgis.com/ apps/opsdashboard/index.html\#/

Ioannou A, Papazafeiropoulou A (2017) Using IT mindfulness to mitigate the negative consequences of technostress. In: AMCIS 2017 proceedings. https://aisel.aisnet.org/amcis2017/AdoptionIT/ Presentations/7

ISO (2021) ISO 45003:2021-occupational health and safety management-psychological health and safety at work-guidelines for managing psychosocial risks. https://www.iso.org/standard/ 64283.html

Jena RK (2015) Technostress in ICT enabled collaborative learning environment: an empirical study among Indian academician. Comput Hum Behav 51:1116-1123. https://doi.org/10.1016/j. chb.2015.03.020

Judge TA, Thorensen CJ, Bono JE, Patton GK (2001) The job satisfaction-job performance relationship: a qualitative and quantitative review. Psychol Bull 127(3):376-407

Junco R (2013) Comparing actual and self-reported measures of Facebook use. Comput Hum Behav 29(3):626-631. https://doi.org/ 10.1016/J.CHB.2012.11.007

Kelliher C, Anderson D (2010) Doing more with less? Flexible working practices and the intensification of work. Hum Relat 63(1):83-106. https://doi.org/10.1177/0018726709349199

Kelloway EK, Francis L (2013) Longitudinal research and data analysis. In: Sinclair RR, Wang M, Tetrick LE (eds) Research methods in occupational health psychology: measurement, design, and data analysis. Routledge/Taylor \& Francis Group, pp 374-394. https://psycnet.apa.org/record/2012-25946-020

Khan RL, Byosiere P (1992) Stress in organizations. Handbook of industrial and organizational psychology. Consulting Psychology Press, Palo Alto, pp 571-650

Kim HJ, Lee CC, Yun H, Im KS (2015) An examination of work exhaustion in the mobile enterprise environment. Technol Forecast Soc Change 100:255-266. https://doi.org/10.1016/j.techfore. 2015.07.009

Korzynski P, Rook C, Florent Treacy E, Kets de Vries M (2020) The impact of self-esteem, conscientiousness and pseudopersonality on technostress. Int Res. https://doi.org/10.1108/ INTR-03-2020-0141

Kossek EE, Thompson RJ, Lautsch BA (2015) Balanced workplace flexibility: avoiding the traps. Calif Manage Rev 57(4):5-25. https://doi.org/10.1525/cmr.2015.57.4.5

Kumar R, Lal R, Bansal Y, Sharma SK (2013) Technostress in relation to job satisfaction and Organisational Commitment among IT professionals. Int J Sci Res Publ 3(12). http://www.ijsrp.org

Lang J, Thomas JL, Bliese PD, Adler AB (2007) Job demands and job performance: the mediating effect of psychological and physical strain and the moderating effect of role clarity. J Occup Health Psychol 12(2):116-124. https://doi.org/10.1037/1076-8998.12.2. 116

Lazarus RS, Folkman S (1984) Stress, appraisal, and coping. Springer, Berlin

Lee C, Lee CC, Kim S (2016a) Understanding information security stress: focusing on the type of information security compliance activity. Comput Secur 59:60-70. https://doi.org/10.1016/j.cose. 2016.02.004

Lee SB, Lee SC, Suh YH (2016b) Technostress from mobile communication and its impact on quality of life and productivity. Total Qual Manag Bus Excell 27(7-8):775-790. https://doi.org/ 10.1080/14783363.2016.1187998

Leiter MP, Durup MJ (1996) Work, home, and in-between: a longitudinal study of spillover. J Appl Behav Sci 32(1):29-47. https:// doi.org/10.1177/0021886396321002

Leka S, Griffiths A, Cox T (2003) Work organisation and stress: systematic problem approaches for employers, managers and trade union representatives. https://apps.who.int/iris/handle/10665/ 42625

Li L, Wang X (2021) Technostress inhibitors and creators and their impacts on university teachers' work performance in higher education. Cogn Technol Work 23(2):315-330. https://doi.org/10. 1007/s10111-020-00625-0

Locke EA (1976) The nature and causes of job satisfaction. In: Dunnette MD (ed) Handbook of industrial and organizational psychology. Rand-McNally, Chicago, pp 1297-1350

Long BC, Schutz RW (1995) Temporal stability and replicability of a workplace stress and coping model for managerial women: a multiwave panel study. J Couns Psychol 42(3):266-278. https:// doi.org/10.1037/0022-0167.42.3.266

López-Araujo B, Osca Segovia A (2008) Un modelo para predecir el tecnoestrés y la satisfacción en teletrabajadores. Revista De Psicología Social Aplicada 18(1):63-85

Lord RG, Kanfer R (2002) Emotions and organizational behavior. In: Lord RG, Klimoski R, Kanfer R (eds) Emotions in the workplace: Understanding the structure and role of emotions in organizational behavior. Jossey-Bass, Hoboken, pp 5-19

Ma Y, Turel O (2018) Information technology use for work and technostress: effects of power distance and masculinity culture dimensions. Cognit Technol Work 21(1):145-157. https://doi. org/10.1007/S10111-018-0503-1

Maier C, Laumer S, Eckhardt A (2015a) Information technology as daily stressor: pinning down the causes of burnout. J Bus Econ 85(4):349-387. https://doi.org/10.1007/s11573-014-0759-8

Maier C, Laumer S, Weinert C, Weitzel T (2015b) The effects of technostress and switching stress on discontinued use of social networking services: a study of Facebook use. Inf Syst J 25(3):275308. https://doi.org/10.1111/isj.12068

Mann S, Holdsworth L (2003) The psychological impact of teleworking: stress, emotions and health. N Technol Work Employ 18(3):196-211. https://doi.org/10.1111/1468-005X.00121

Marchiori DM, Mainardes EW, Rodrigues RG (2019) Do individual characteristics influence the types of technostress reported by workers? Int J Hum Comput Interact 35(3):218-230. https://doi. org/10.1080/10447318.2018.1449713

Marshall J, Burd C, Burrows M (2021) working from home during the pandemic. US Census Bureau. https://www.census.gov/library/ stories/2021/03/working-from-home-during-the-pandemic.html

Matthews RA, Wayne JH, Ford MT (2014) A work-family conflict/ subjective well-being process model: a test of competing theories of longitudinal effects. J Appl Psychol 99(6):1173-1187. https:// doi.org/10.1037/a0036674

Medina Cartagena MA (2020) Las oficinas después del coronavirus. El Espectador. https://www.elespectador.com/noticias/economia/ las-oficinas-despues-del-coronavirus/

Menard S (2002) Longitudinal research. Sage, Thousand Oaks

Michie S (2002) Causes and management of stress at work. Occup Environ Med 59(1):67-72. https://doi.org/10.1136/OEM.59.1.67

Molino M, Ingusci E, Signore F, Manuti A, Giancaspro ML, Russo V, Zito M, Cortese CG (2020) Wellbeing costs of technology use during Covid-19 remote working: an investigation using the Italian translation of the technostress creators scale. Sustainability (switzerland) 12(15):5911. https://doi.org/10.3390/SU12155911

NICE (2009) Mental wellbeing at work. https://www.nice.org.uk/guida nce/ph22

Nilles JM (1997) Telework: enabling distributed organizations: implications for it managers. Inf Syst Manag 14(4):7-14. https://doi. org/10.1080/10580539708907069

Park Y, Haun VC (2018) The long arm of email incivility: transmitted stress to the partner and partner work withdrawal. J Organ Behav 39(10):1268-1282

Qi C (2019) A double-edged sword? Exploring the impact of students' academic usage of mobile devices on technostress and academic 
performance. Behav Inf Technol 38(12):1337-1354. https://doi. org/10.1080/0144929X.2019.1585476

Ragu-Nathan TS, Tarafdar M, Ragu-Nathan BS, Tu Q (2008) The consequences of technostress for end users in organizations: conceptual development and validation. Inf Syst Res 19(4):417-433. https://doi.org/10.1287/isre.1070.0165

Ringle CM, Wende S, Becker J-M (2015) SmartPLS 3. http://www. smartpls.com

Ritter KJ, Matthews RA, Ford MT, Henderson AA (2016) Understanding role stressors and job satisfaction over time using adaptation theory. J Appl Psychol 101(12):1655-1669. https://doi.org/10. 1037/apl0000152

Roemer E (2016) A tutorial on the use of PLS path modeling in longitudinal studies. Ind Manag Data Syst 116(9):1901-1921. https:// doi.org/10.1108/IMDS-07-2015-0317

Rothmann S (2008) Job satisfaction, occupational stress, burnout and work engagement as components of work-related wellbeing. SA J Ind Psychol 34(3):11-16. http://www.scielo.org.za/scielo.php? pid=S2071-07632008000300002\&script=sci_arttext\&tlng=es

Sarabadani J, Carter M, Compeau D (2018) 10 years of research on technostress creators and inhibitors: synthesis and critique. AMCIS 2018 proceedings. https://aisel.aisnet.org/amcis2018/ AdoptionDiff/Presentations/23

Sardeshmukh SR, Sharma D, Golden TD (2012) Impact of telework on exhaustion and job engagement: a job demands and job resources model. N Technol Work Employ 27(3):193-207. https://doi.org/ 10.1111/j.1468-005X.2012.00284.X

Sarstedt M, Hair JF, Ringle CM, Thiele KO, Gudergan SP (2016) Estimation issues with PLS and CBSEM: where the bias lies! J Bus Res 69(10):3998-4010

Schleicher DJ, Watt J, Greguras GJ (2004) Reexamining the job satisfaction-performance relationship: the complexity of attitudes. J Appl Psychol 89(1):165-177. https://doi.org/10.1037/0021-9010. 89.1.165

Sonnentag S, Frese M (2003) Stress in organizations. Handbook of psychology. Wiley, New York, pp 453-491. https://doi.org/10. 1002/0471264385.wei1218

Springer GJ (2011) A study of job motivation, satisfaction, and performance among bank employees. J Glob Bus Issues 5(1):29-42. https://search.proquest.com/openview/fd8503973f2c32043fa0 f9b1f55c2f04/1 ?pq-origsite $=$ gscholar $\& \mathrm{cbl}=39974$

Srivastava SC, Chandra S, Shirish A (2015) Technostress creators and job outcomes: theorising the moderating influence of personality traits. Inf Syst J 25(4):355-401. https://doi.org/10.1111/isj.12067

Suh A, Lee J (2017) Understanding teleworkers' technostress and its influence on job satisfaction. Int Res 27(1):140-159. https://doi. org/10.1108/IntR-06-2015-0181

Tams S, Thatcher JB, Grover V (2018) Concentration, competence, confidence, and capture: an experimental study of age, interruption-based technostress, and task performance. J Assoc Inf Syst 19(9):857-908. https://doi.org/10.17705/1jais.00511

Tarafdar M, Tu Q, Ragu-Nathan BS, Ragu-Nathan TS (2007) The impact of technostress on role stress and productivity. J Manag Inf Syst 24(1):301-328. https://doi.org/10.2753/MIS0742-12222 40109

Tarafdar M, Tu Q, Ragu-Nathan T (2010) Impact of technostress on end-user satisfaction and performance. J Manag Inf Syst 27(3):303-334. https://doi.org/10.2753/MIS0742-1222270311

Tarafdar M, Tu Q, Ragu-Nathan TS, Ragu-Nathan BS (2011) Crossing to the dark side: examining creators, outcomes, and inhibitors of technostress. Commun ACM 54(9):113-120. https://doi.org/10. 1145/1995376.1995403

Tarafdar M, Pullins EB, Ragu-Nathan TS (2015) Technostress: negative effect on performance and possible mitigations. Inf Syst $\mathbf{J}$ 25(2):103-132. https://doi.org/10.1111/isj.12042 ter Hoeven CL, van Zoonen W (2015) Flexible work designs and employee well-being: examining the effects of resources and demands. N Technol Work Employ 30(3):237-255. https://doi. org/10.1111/ntwe.12052

Tietze S, Musson G (2005) Recasting the home-work relationship: a case of mutual adjustment? Organ Stud 26(9):1331-1352. https:// doi.org/10.1177/0170840605054619

Tu Q, Wang K, Shu Q (2005) Computer-related technostress in China. Commun ACM 48(4):77-81. https://doi.org/10.1145/1053291. 1053323

Tu Q, Tarafdar M, Ragu-Nathan TS, Ragu-Nathan BS, Ragu-Nathan $\mathrm{T}$ (2008) Improving end-user satisfaction through techno-stress prevention: some empirical evidences. In: AMCIS 2008 proceedings, pp 1-8. http://aisel.aisnet.org/amcis2008/236

Tucker JS, Sinclair RR, Mohr CD, Adler AB, Thomas JL, Salvi AD (2008) A temporal investigation of the direct, interactive, and reverse relations between demand and control and affective strain. Work Stress 22(2):81-95. https://doi.org/10.1080/02678 370802190383

Unilibre (2020) Teletrabajo y trabajo en casa, dos conceptos muy distintos. https://www.dinero.com/hablan-las-marcas/articulo/telet rabajo-y-trabajo-en-casa-dos-conceptos-muy-distintos/305284

Vanderhaegen F (2021) Weak signal-oriented investigation of ethical dissonance applied to unsuccessful mobility experiences linked to human-machine interactions. Sci Eng Ethics 27(1):1-25. https://doi.org/10.1007/S11948-021-00284-Y

Verbeke A, Schulz R, Greidanus N, Hambley L (2008) Growing the virtual workplace: the integrative value proposition for telework. Edward Elgar, Cheltenham

Viswesvaran C, Ones DS (2000) Perspectives on models of job performance. Int J Sel Assess 8(4):216-226. https://doi.org/10.1111/ 1468-2389.00151

Wall TD, Michie J, Patterson M, Wood SJ, Sheehan M, Clegg CW, West M (2004) On the validity of subjective measures of company performance. Pers Psychol 57(1):95-118. https://doi.org/ 10.1111/j.1744-6570.2004.tb02485.x

Wang K, Shu Q, Tu Q (2008) Technostress under different organizational environments: an empirical investigation. Comput Hum Behav 24(6):3002-3013. https://doi.org/10.1016/J.CHB.2008. 05.007

Weinert C, Weitzel T (2019) How do users cope with technostress over time? A longitudinal study investigating the intra-individual effects of technostress mitigation. In: DIGIT 2019 proceedings. https://aisel.aisnet.org/digit2019/11

Weinert C, Maier C, Laumer S (2015) Why are teleworkers stressed? An empirical analysis of the causes of telework-enabled stress. In: Thomas O, Teuteberg F (eds) 12th international conference on Wirtschaftsinformatik, pp 1407-1421

World Health Organization (2001) Declaration of Helsinki-World Medical Association Declaration of Helsinki. Bull World Health Organ 79(4):373-374. https://www.who.int/bulletin/archives/ 79(4)373.pdf

Zapf D, Dormann C, Frese M (1996) Longitudinal studies in organizational stress research: a review of the literature with reference to methodological issues. J Occup Health Psychol 1(2):145-169. https://psycnet.apa.org/buy/1996-04478-004

Publisher's Note Springer Nature remains neutral with regard to jurisdictional claims in published maps and institutional affiliations. 